\title{
Opacity in International Legal Texts: Generic Trait or Symbol of Power?
}

\author{
María Ángeles Orts \\ University of Murcia \\ mageorts@um.es
}

\begin{abstract}
Due to this international character of English, texts in this language -as proffered by several major institutions in the area of public and private laware deployed as necessary tools of communication in the course of the establishment of transnational commercial and juridical relationships. However, English as the language of the law has been branded as a complex, opaque, kind of discourse. The aim of the present paper is to address the question of the undeniable complexity of legal texts in English as instruments to wield power, their unveiled communicative aim being to separate the ruler from the citizen and the legal message from its user. To demonstrate the validity of such thesis, genre analysis has been applied to three paradigmatic texts, consequential to develop international deals in the transnational contexts: the insurance policies of the London Institute of Underwriters at Lloyd's, the Rules issued by the London Court of international Arbitration and the Geneva Convention on the Contract for the International Carriage of Goods by Road (CMR). The goal of our study will be carried out through different levels to discern whether there exists any possible equation between power and textual complexity: the formal and discursive level, which will scrutinize lexicon, syntax and textual elements (macrostructure of texts and metadiscourse markers) and the pragmatic level, which will study the texts as peculiar generic types of legal agreements where power and commitment between the parties as a set of directives, i.e. obligations exerted by a powerful party over another, the recipient of the text.
\end{abstract}

Keywords: legal language, power, CMR, Institute Cargo Clauses, LCIA 


\section{1. Introduction: complexity in legal English}

The present work undertakes the study of two major international legal texts: the Geneva Convention on the Contract for the International Carriage of Goods by Road, (henceforth CMR) and the Arbitration Rules of the International Chamber of Commerce (henceforth ICC), which constitute examples of the role of English as the international medium of professional communication and of the globalization of legal transactions. Our purpose overall will be to determine whether these texts are formally and discursively opaque because they obey to the necessary technical character of English legal texts at large, or because they constitute clear examples of a "dominant discourse" (Bourdieu, 1991) which disguises the wielding of power and power relations (Evangelisti Allori, 2008).

Due to their international transcendence, English legal texts, as proposed by several major institutions in the area of public and private law, are deployed as necessary tools of communication in the establishment of transnational commercial and juridical relationships. Changes in technology and communication have made global contact and cooperation imperative for political and economic reasons: law firms, law schools, universities, courts and other legal institutions must render themselves more "international" to support the national interests of their clients and governments. Consequently, the globalization of business activities and dispute resolution through arbitration between individuals and institutions has been accompanied by a process of 'legal internationalization' (Klabbers and Sellers, 2008: 4). However, internationalization is essentially a verbal process which requires a common language for legal officials and scholars to understand one another, and the language is, undeniably, English (Crystal, 1997: 8-10). However, there are adverse side effects to the character of English as an international professional communication tool: language being the key to the construction of reality, the adoption of English as the instrument of legal communication has also entailed the predominance of English logic, worldview and preferences (Focarelli, 2012: 93).

The emergence of a relatively new audience -non-native speakers of English who use the language as a professional lingua franca- has advocated for the creation of plain English legal documents adapted to this audience's specific needs. Nevertheless, "the Plain English movement has not yet revolutionized English-language legal writing" (Hammell, 2008: 289), and English legal language is still an intricate and elaborate form of discourse. Such complexity has been widely discussed by lawyers, linguists and translators over the years (Alcaraz and Hughes, 2002; Cao, 2007; Tiersma, 1999), with the general agreement that legal language is complex because it has to fit the complex social reality that is law (Palmirani et al, 2012). Indeed, supporters of legal language complexity purport that such so-called legalese is more precise and specific than plain language (Siegel and Etzkorn, 2013), and that the texts of the law cannot be simplified without sacrificing their legal force and certainty: legal language is conservative by definition and makes use of established formulae which have been tested before courts for centuries. Since these are used by law professionals with confidence, they are considered 'safe'; it has even been argued that choosing to adopt new, more 
domesticated formulations carries a risk of "unsuspected deficiencies" (Crystal and Davy 1969: 194). The reluctance to change this traditional stance is attributed to several factors, among which that of inertia: lawyers uncritically perpetuate the style they have always used, which is transmitted by law schools and reinforced in legal practice. In the adversarial context of Anglo-Saxon law, change is sensed as leading to uncertainty and textual simplicity to ambiguity particularly with regard to a hostile interactant looking for loopholes in a case. There is also a clear need for safety: as pointed out above, the traditional style of legal drafting is 'safe', while plain language is not; many terms and phrases have judicially-defined meanings, and substituting a modern term is to lose the benefit of that judicial definition (Butt, 2001: 29-30).

On the other hand, those who attack legal language as being unnecessarily complex (among them, the supporters of the so-called Critical Law Studies, CLS ${ }^{1}$ ) state that law is an authoritative and sophisticated institution which affects and influences every aspect of social life, and which is based upon the deployment and possession of power. According to Salmi Tolonen (2011:1), neither language nor law in themselves have any purpose or power whatsoever, but they become powerful in the hands of those who hold institutional power, and power must be exercised according to the rules laid down by such authority (McDowell, 2010: 160). The power wielded by law as an institution is an instrumental power: the explicit power of the sort imposed by the state, by its laws and conventions or by the organizations for which we work (Barnett and Duvall, 2004; Cutler, 2003). However, the great source of the law's power is the language through which it enforces, reflects, constitutes, and legitimizes dominant social and power relations without a need for or the appearance of control from outside (Kairys, 1999).

The hypothesis underlying this work is, therefore, that opacity in legal texts may be connected to the authoritative, mandatory character of the specialised communities that issue them. The acquisition or exhibition of supremacy is achieved through the technicality, precision and complexity of the law's written texts (Gibbons, 2004), which represent an intentional exercise of elitist and exclusionary practices (Goodrich, 1987). Social and professional status in a society in which the law plays an important role is a determining factor contributing to the conservatism and technicality of the language of the law (Tiersma, 1999: 3). The perception of legal language as a "frozen genre" (Bhatia, 2004) or a "fossilized language" (Alcaraz and Hughes, 2002: 9) is partly due to the institutional character of legal discourse, its social detachment from the user and the hierarchical order it wishes to establish.

\section{Our corpus in context}

As advanced in the previous section, the present work aims to study two paradigmatic texts which play a consequential role in the development of international transactions in transnational contexts. The CMR and ICC Rules analysed in the context of this study have a predominantly normative content, since they regulate road transport and a particular process of international arbitration, respectively. Nevertheless, as Gotti 
warns, "the formulation of legal concepts in normative texts in multilingual/multicultural contexts is greatly conditioned by specific economic and sociocultural factors" (2008: 41), which amounts to stating that legal texts with the same regulative purpose are drafted and constructed differently, depending on the legal, cultural and linguistic contexts they spring from. This will be the point of departure from which we will sustain our present research.

Figure 1 illustrates how international legal texts are organized in the area of commerce:

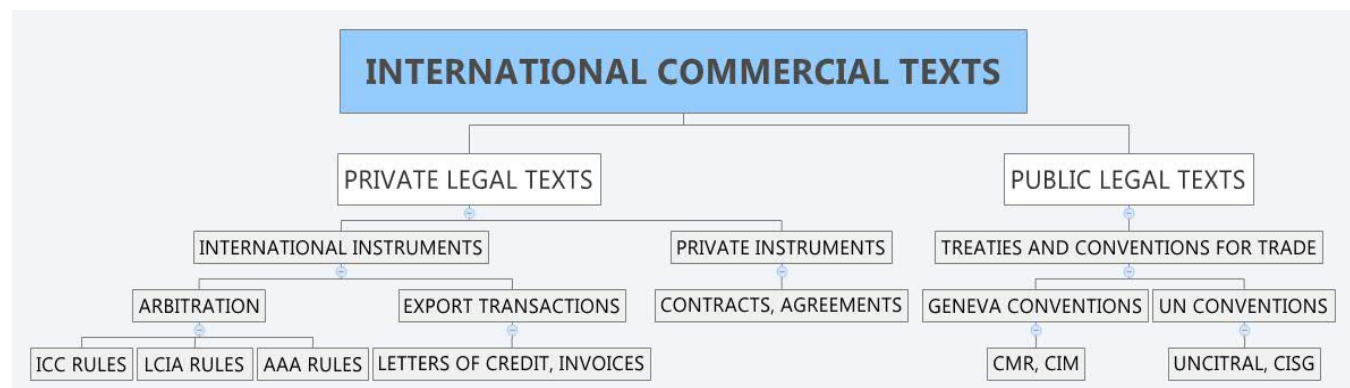

Figure 1. International commercial legal genres

Though the typology and variety of texts in this area are in fact even wider and, as such, susceptible to multiple classifications regarding different aspects of international trade, their purposes and other issues (Hillier, 1998), the presentation in Figure 1 is an attempt to reduce the panorama to manageable proportions and explain the area in which each of the documents that we aim to analyse is situated. As can be seen in the Figure, international economic law is subdivided into public and private law. The former regulates economic relations between states and organizations through Conventions and Treaties, as supranational agreements, whereas the latter is a branch of civil law that controls and standardizes agreements and transactions between private parties, either companies or individuals. Public international law covers a vast number of treaties and conventions; in the private sphere of international law (deservingly called 'conflict of laws') there are several domains of interest, among which export transactions, arbitrage and private instruments regulating individual operations are included.

The CMR (bottom right-hand side of Figure 1) is one of the Geneva Conventions that deal with commercial transactions, on a par with the CIM, which regulates transport of goods by rail. It was adopted by the United Nations Economic Commission for Europe in 1956, and deals with carriage regulations for international road transport operations, determining the rights and responsibilities of the carrier, consignor and consignee and of each transaction. The CMR Convention belongs to the area of public law, since every road expedition that starts or finishes in countries which have ratified it (41, most of them in the European Continent ${ }^{2}$ ), is subject to its stipulations. Usually contracts are confirmed by the issue of a CMR consignment note, which must show the name and address of the consignee, consignor and carrier, a description of the goods, weight and number of packages, etc. In other words, the CMR is both a treaty and the 
standardized conditions of a due road transport transaction; in the present study, however, we will deal with the CMR only in its modality as an international agreement, and not as a transport document.

On the left-hand side of Figure 1 is the second subcorpus of our study: the Arbitration Clauses of the International Chamber of Commerce (ICC). The ICC Court of Arbitration was established in Paris in 1923. Because of its transnational character (which makes it different from the London Court of Arbitration, LCIA or those of the American Arbitration Association, AAA), it remains "the world's leading international commercial arbitration institution and has less of a national character than any other arbitral institution" (Born, 2001: 13). They are, in fact, a result of discussion maintained between dispute resolution experts and representatives of the business community from seventy-five countries.

To further clarify the nature of our documents, we refer to Trosborg's taxonomy on international documents (1997), according to which international texts are classified as 'pure' and 'hybrid'. The former are those which resist change across cultures, being most often the product of a dominant culture (Trosborg, 1997: 145-146 ${ }^{3}$ ), while the latter -like EU directives or UN treaties and Conventions- are the result of compromise between cultures. Being a 'pure' or hybrid' text also has an incidence on its relative complexity, since 'pure' international texts are imposed on the community, while meaning in hybrid texts has to be negotiated. Therefore, since our texts are drafted in two official versions, English and French, and have to be accepted by a wide and large community of users, we consider them as hybrid instances of texts, but with differing levels of hybridity. Such dissimilarities in hybridity, as we shall see below, have their ultimate origin in the different communicative purposes of the institutions where they have their origin, namely the United Nations Commission for Europe (ECE) that issues the CMR Convention, and the Court of International Arbitration at the International Chamber of Commerce issuing the ICC. The former is the originator of an international agreement that has to bind states, sides, or military forces on a specific subject, and needs to be interpreted in the same way by the courts in the countries which are parties to the convention in order to promote uniformity. In contrast, the Rules (issued in all the major thirteen languages used in international trade) are part of the ADR (Alternative Dispute Resolution), where the choice of arbitration is a discretional process, and the language, the venue and the substantive and procedural law depend on the participants' choice. Therefore, unlike the CMR Convention (that offers no alternative norms for the transportation of cargo in the signatory countries), the ICC Rules are presented as one among many methods of arbitration, in competition with those offered by the rest of the courts in the world and ostensibly should be more easily interpreted and understood by a plural community. We hence predict that this degree of hybridity is going to have an incidence on the ways in which either document is drafted, translating a more hybrid nature into greater clarity of meaning. 


\section{Narrowing the purpose and method of our study: genres and power}

The study of power in language is gaining momentum in the area of specialized discourse studies, with rising interest in the role that is played by personal interactions in the elaboration and application of specialized texts, and in the analysis of bureaucratization in the contexts of banking and education (Breeze, 2013; Breeze et al, 2014; Sarangi and Slembrouck, 2014). Language control and manipulation for the achievement of social power have been traditionally studied, among others, by Critical Linguistics or CL (Fowler et al, 1979; Kress and Hodge, 1979) and Critical Discourse Analysis or CDA (Fairclough, 1989; now in a revised third edition 2014). Both currents are closely interconnected, but the former specifically aims to analyze the discursive strategies deployed to legitimately control or 'naturalize' the social order, while the latter studies the opaque processes of domination through language, explaining how language constitutes a powerful social tool at the service of the dominant. Even if the present study is not specifically based upon any of the two doctrines, it does depart from Fairclough's critical notion of discourse as language use in social practice, which focuses not only upon language and its structuring, but also on the linguistic characteristics of social and cultural processes (Mirzaee and Hamidi, 2012).

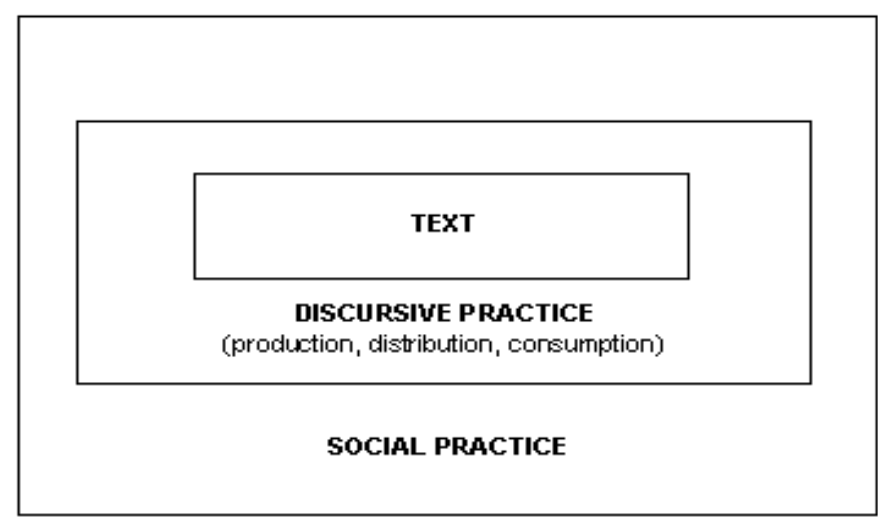

Figure 2. Fairclough's Dimensions of Discourse. (From Doyle, 2003)

As we can see in Figure 2, Fairclough's analytic framework includes three levels of scrutiny: the text, the discursive practice, and the sociocultural practice. For Fairclough, the analysis of any text consists of the study of the language structures produced in a discursive event, and how these are part of the discursive practices of a social group. This vision of discourse as a social practice constitutes not a method, but an approach to the analysis of power in discursive practices. Today, such an approach can benefit from the methodologies deployed by genre studies, the trend of linguistics that explains text typologies as structured communicative events designed to enable a due community to legitimately attain their professional purposes. Stemming from Systemic Functional Linguistics and English for Specific Purposes theories, genre theory explains the internal communicative mechanisms that take place among the members of professional and/or specialised communities, as well as between these members and society as a 
whole. Hence, the purpose of this work is to analyse our international texts both as an illustrative example of English legal discourse and as genres in their own right, and unravel the interactive entanglement between the participants (law-makers and lawtakers) in the communicative acts that the Convention and the Rules constitute.

In the context of the present study, the CMR and ICC are to be considered as genres used to guide, control, or change the behaviour of agents with decision-making capacities (Hermans, 1996). As such, they constitute the manifestation of the communicative strategies of an institutional collectivity that produces norms to be imposed on a specific audience: the parties to a road transport transaction, on the one hand, and the prospective clients of an Alternative Dispute Resolution, ADR, dispute, on the other. The texts will be scrutinized at different levels to discern whether there is any possible equation between their prescriptive character and their quintessential textual complexity. The textual level will account for the presence of words of archaic origin, ritualistic language, specific, technical words, peculiar to legal discourse -which Mellinkoff labelled as 'terms of art' (1963: 63) - and density and length in syntactic construction; the discursive level will scrutinize textual elements visible both in the supra-organisation or macrostructure of texts and in their metadiscourse markers; finally, the pragmatic level will study the texts as particular generic types of legal agreements where power and commitment between the parties is not established in the form of a symmetrical relationship but as a set of directives, i.e., obligations exerted by one powerful party over another, the recipient and addressee of the text.

Specifically, our study at Fairclough's textual level will account for the presence of what Crystal and Davy labelled the 'surface elements' (1969:201), i.e., the substance, or 'raw material' of the text, as well as the particular combinations which can develop into higher units. The study of lexicon and grammar in isolation may not render conclusive results but, considered in the light of our subsequent levels of analysis, it may uncover interesting functional variables. Scrutiny at lexical level will take into account the linguistic choices made as instances of legal discourse, namely the use of technical terms, archaisms and formal and ritual language. A second part will take stock of syntactic choices concerning sentence density and length.

Additionally, the discursive elements of specialised texts are visible in their supraorganisation or macrostructure and in their metadiscourse markers. On the one hand, the macrostructure plays a defining role in framing the textual segment in accordance with the conventionalised social knowledge at the disposal of the discursive or professional community, and how this is organised in the text. On the other hand, the study of metadiscourse markers complements this discursive scrutiny. These markers constitute the set of strategies that reveal the existence of an interpersonal relationship, a dialogical framework between writers and readers of texts (Hyland, 2005; Hyland and Tse, 2004; Dafouz, 2008, among many others). Since writers or speakers do not simply produce a text to convey information and to represent an external reality, but to project themselves in their texts when interacting with their receivers, metadiscourse plays an important role in organizing the discourse, engaging the audience and signalling the writer's or speaker's attitude (Fuertes-Olivera et al., 2001). Since legal texts are 
designed as monologic texts intended to be interpreted rather than read and understood, the concept of interpersonality has usually been unheeded in this area and prototypically been linked to fields other than law and its genres. In view of this, the present article will attempt to discern patterns of difficulty or clarity underlying the texts, or, rather, the ways in which law-makers seek to organize information in a coherent and convincing way for addressees.

The final level of our study will focus on expliciting the implicit power relationships embedded in the text. Looking at language from its social perspective implies introducing a description of language in use, the specification of its pragmatic discursive meaning, and confronting the linguistic aspects of textual construction and interpretation with the sociocultural factors that underlie the text. The pragmatic or social level will study the texts as specific generic types of legal covenants where power and commitment between parties are not established in the form of a symmetrical relationship but as a set of directives, i.e., obligations exerted by one powerful party over the recipients of the text. Accordingly, we will undertake a study both of the direct directives in the texts -those intended to impose obligation and prohibition-, and of the indirect ones -those intended to attribute rights and grant permission-, with a view to discerning how differently or similarly power between participants is distributed in each text, and how such distribution correlates with the results obtained at textual and discursive levels.

\section{Analysis and discussion}

\subsection{Textual level}

To take stock of the main formal traits of our corpus, we first carried out a lexical analysis which filtered the technical terms. As mentioned above, Mellinkoff (1963) remarks on the existence of specialized terms peculiar to the law (such as 'claimant', 'joinder' or 'waiver', for example) which he calls 'terms of art' and which, as we shall see, are present in both subcorpora. But in the context of technical terms, it is also worth mentioning Tiersma's view that, in the law, absolute and fixed meanings are not essential, nor are they usually attainable. In fact, a technical term is also one (such as 'carrier', 'award', 'hearing' or 'expenses') that is being used by a specific discipline, either exclusively, or as a deviation from 'normal meaning' (Tiersma, 1999: 100-115). Tiersma additionally affirms that, not only does the law have its own 'special' terms, but "the legal subdisciplines have their own terminology, and sometimes a term may differ in meaning according to specialty" (1999: 108). This specificity according to subdisciplines is clearly manifest in our corpus, as we will see later on.

Additionally, technical specificity in legal language often goes hand in hand with formal and ritual words. We analysed the ritual and formal traits of our corpus according to the presence of lexical doublets or binomials (Tiersma, 1999: 111), infrequent prepositional combinations like 'hereby' or 'theretofore', and archaic words, 
often of Latin and French origin. Finally, syntactic complexity is also the rule in legal English. Sentences approximating a hundred words or more are common, when legal drafters advise that sentences should be 20 to 30 words long at most (Garner, 2001). Legal syntax is made up of complex structures embedded into one another and the overuse of conditionals with complex prepositional phrases. Passive structures obscure the agent of the sentence and make the prose heavy and unclear. Such convoluted syntax renders comprehension difficult and infuses legal texts with negative and threatening undertones.

Results at this level were collected in different ways. Lexical frequencies and sentence length were obtained with the Wordlist/Statistics Tool of Wordsmith Tools 3.0 and parsed manually; typologies of terms were classified with the aid of Black's Law Dictionary and Merriam Webster Dictionary Online.

\subsubsection{Textual aspects of the CMR}

The CMR corpus contains a total of 8,078 words/tokens and 1,018 types, or distinct words without repetitions. However, only 300 types were selected, after discounting words of low-information value such as prepositions, pronouns, modal verbs (to be analysed elsewhere) and finite forms of 'be' and 'have'. Once such parsing completed, we proceeded to work with our dictionaries of reference selecting the terms in the corpus manually. The results divide the terms of art of the CMR subcorpus into three distinguishable areas: firstly, words relating to the Convention and its parts (notably, its articles, paragraphs and provisions), secondly, terms referring to the world of road carriage and, finally, a substantial number of verbs and nouns related to legal obligations and limitations. The terms and frequencies of these three categories are shown in the tables below:

\begin{tabular}{|l|c|}
\hline TERM OF ART & FREQUENCY IN TOKENS \\
\hline Total & $\mathbf{4 1 9}$ \\
\hline ARTICLE & 175 \\
\hline CONVENTION & 59 \\
\hline PARAGRAPH & 52 \\
\hline PROVISION & 32 \\
\hline CHAPTER & 18 \\
\hline CMR & 15 \\
\hline SECRETARY-GENERAL & 15 \\
\hline ACCESSION & 15 \\
\hline TRIBUNAL & 12 \\
\hline RATIFICATION & 10 \\
\hline CONFERENCE & 7 \\
\hline CLAUSE & 5 \\
\hline PREAMBLE & 4 \\
\hline
\end{tabular}

Table 1: Terms relating to the CMR Convention 


\begin{tabular}{|l|c|}
\hline TERM OF ART & FREQUENCY IN TOKENS \\
\hline Total & $\mathbf{4 9 2}$ \\
\hline CARRIER & 138 \\
\hline GOODS & 103 \\
\hline CARRIAGE & 63 \\
\hline CONSIGNMENT & 45 \\
\hline SENDER & 30 \\
\hline DELIVERY & 28 \\
\hline CONSIGNEE & 27 \\
\hline PLACE & 22 \\
\hline PACKAGES/PACKING/ & 9 \\
PACKAGING & 6 \\
\hline AGENTS & 6 \\
\hline VEHICLE & 6 \\
\hline TERRITORY & 6 \\
\hline SERVANT & 3 \\
\hline WEIGHT & \\
\hline
\end{tabular}

Table 2: Terms relating to road transport in CMR.

\begin{tabular}{|l|c|}
\hline TERM OF ART & FREQUENCY IN TOKENS \\
\hline Total & $\mathbf{4 5 7}$ \\
\hline CONTRACT & 51 \\
\hline LOSS & 43 \\
\hline CASE/S & 38 \\
\hline DAMAGE & 37 \\
\hline LIABILITY/LIABLE & 37 \\
\hline CLAIMANT/CLAIM & 31 \\
\hline ENTITLED & 30 \\
\hline PARTY & 28 \\
\hline RIGHT & 19 \\
\hline ACTION & 17 \\
\hline DELAY & 15 \\
\hline CHARGES & 14 \\
\hline COURT & 12 \\
\hline PERFORMANCE & 10 \\
\hline RESPONSIBLE & 9 \\
\hline TERMS & 9 \\
\hline REASONABLE & 9 \\
\hline PROCEEDINGS & 8 \\
\hline BURDEN & 5 \\
\hline NEGLECT & 5 \\
\hline WILFUL & 5 \\
\hline WRONGFUL & 5 \\
\hline DEFAULT & 4 \\
\hline DISPUTE & 4 \\
\hline EVIDENCE & 4 \\
\hline INSTRUMENT & 4 \\
\hline JUDGEMENT & 4 \\
\hline Table $3:$ Geral & \\
\hline
\end{tabular}

Table 3: General legal terms in CMR.

All in all, the number of terms analysed in the text amounts to 56, 13 of them pertaining to the Convention itself, 15 to road transport and 27 to the area of general legal terms, respectively. In terms of comparison with the words in the subcorpus as a whole, the lexicon in the text has a terminological specificity of $12.7 \%$. As seen in 
Table 1, the terms relating to the Convention refer mainly to the parts into which it is divided (the most frequent word overall in the subcorpus of this group being 'article'). The main actor referred to is that of the Secretary-General, but the Convention itself -as we shall see below- often takes on the role of one of the main characters, seemingly regarded as an 'animate' entity. Table 2, in turn, focuses on the parties to the transportation contract, mainly 'the carrier', 'the sender', 'the consignee' and their agents and servants. Other factors and processes of the transaction such as 'carriage', 'consignment' or 'delivery' are prominent in this group. The last group relating to general legal terms is one with a predominant presence in the CMR, as befits a text with a predominantly juridical flavour.

Formality and rituality are manifest in traits typical of legalese, such as binomials, polysyllabic words of archaic origin and pronominal adverbs in combinations. Binomials in this subcorpus consist of native and French or Latin terms where, as a rule, one term explains or complements the other (as in 'loss and damage' and 'costs and expenses'), or where the binomial contains words originating from the same linguistic source (as in 'null and void'). Formality is also present in the incorporation of Latin collocations (prima facie, per annum, per centum) and in the abundant use of polysyllabic words -34 types- of Latin origin ('stipulation', 'conversion', 'convention', 'construction'), from Old French ('commencement', 'judgement', 'damage', 'indemnification', 'preamble', 'prejudice'), from Anglo-French ('claimant', 'dangerous', 'carriage'), or from Middle French ('expiration', 'ratification', 'protocol'). Additionally, the text shows 13 instances of such typical legalese combinations as 'there+preposition' ('thereupon', 'thereafter', 'hereby', 'therein' and 'thereto') and 164 occurrences of the verb 'shall' in its ritual sense, with a mandatory or a performative character (Tiersma, 1999: 105).

Regarding syntactic aspects, the text also seems to follow classic patterns regarding length and convolution of legal texts at large. There are 211 sentences, with an average length of 36.87 words per sentence. There are several examples of very long sentences, 134 words (article 232, section 9) and 113 words (article 30, section 1), with the longest reaching 164 words (article 2). Syntactic complexity is also apparent in the marked preference for subordination to coordination, the frequent use of legal qualifications to introduce exceptions or inclusions in the sentences, and an abundance of conditional sentences with 'if', 'unless' or 'provided that', as for example in the extract below:

[If the carriage is performed in vehicles specially equipped to protect the goods from the effects of heat, cold, variations in temperature or the humidity of the air Qualification 1], the carrier shall not be entitled to claim the benefit of article 17, paragraph 4 (d) [main sentence], [unless he proves that all steps incumbent on him in the circumstances with respect to the choice, maintenance and use of such equipment were taken and that he complied with any special instructions issued to him Qualification 2] (Article 18, Section $4)$.

A final but nevertheless consequential trait present in the text is the common use of passive structures. The desire for impersonality of legal texts in general is present 
through the 31 passive constructions in our corpus, mainly used in the context of imposing 'universal' and 'impartial' obligations or penalties to the parties, as in:

The consignee shall be entitled to require the carrier to deliver to him, against a receipt, the second copy of the consignment note and the goods (Article 13, Section 1)

The same provision shall apply if the wilful misconduct or default is committed by the agents or servants of the carrier (Article 29, Section 2)

\subsubsection{Textual aspects of ICC Rules}

The ICC subcorpus contains a total of 8,713 words/tokens and 891 types or distinct words without repetitions. However, 320 lexical tokens with an informative value have been selected according to the criteria above, and the categories in this document are lower in number than those in the CMR. In fact, the terms of art in this subcorpus which has a $20.3 \%$ higher terminological specificity rate than that of the CMR- are restricted solely to two areas, i.e., those belonging to the scope of arbitration and general legal terms.

In the first group (with 17 terms), we have included terms that refer mostly to the personalia evoked in the text, i.e., the parties to the process -such as the 'Arbitrator', the 'Secretariat', the 'President' and 'Vice-President'-, and also to the different aspects pertaining more specifically to arbitration and its different stages, such as 'award', 'mediation', '(arbitration) agreement' and 'rules (of the Court)'.

\begin{tabular}{|l|c|}
\hline \multicolumn{1}{|c|}{ TERM OF ART } & $\begin{array}{c}\text { FREQUENCY IN } \\
\text { TOKENS }\end{array}$ \\
\hline Total & $\mathbf{7 0 9}$ \\
\hline ARBITRATOR & 201 \\
\hline ICC & 103 \\
\hline SECRETARIAT & 77 \\
\hline MEDIATOR & 64 \\
\hline AWARD & 60 \\
\hline PRESIDENT & 55 \\
\hline MEDIATION & 41 \\
\hline ARBITRATION AGREEMENT & 25 \\
\hline SECRETARY GENERAL & 20 \\
\hline COMMITTEE & 19 \\
\hline COURT (OF ARBITRATION) & 15 \\
\hline VICE-PRESIDENT & 11 \\
\hline PRESIDENT (OF THE COURT) & 7 \\
\hline SECRETARIAT OF THE COURT & 4 \\
\hline CO-ARBITRATOR & 3 \\
\hline DEPUTY SECRETARY GENERAL & 2 \\
\hline GENERAL COUNSEL & 2 \\
\hline
\end{tabular}

Table 4: Terms relating to Arbitration in ICC 
The second group consists of 21 terms that refer to the legal character of the process, with terms such as 'claim', 'counterclaim', 'party/ies',' costs', 'court', 'dispute', 'proceedings' and 'waiver'.

\begin{tabular}{|l|c|}
\hline \multicolumn{1}{|c|}{ TERM OF ART } & FREQUENCY IN TOKENS \\
\hline Total & $\mathbf{1 0 6 0}$ \\
\hline PARTY/IES & 353 \\
\hline ARTICLE/S & 233 \\
\hline CLAIM/S & 81 \\
\hline DISPUTE & 76 \\
\hline EXPENSES & 70 \\
\hline COSTS & 68 \\
\hline PROCEEDINGS & 52 \\
\hline CLAIMANT & 24 \\
\hline RESPONDENT & 19 \\
\hline COUNTERCLAIM & 15 \\
\hline HEARING & 13 \\
\hline LAW & 13 \\
\hline CONTRACT & 8 \\
\hline JOINDER & 8 \\
\hline RULES (OF LAW) & 6 \\
\hline EVIDENCE & 5 \\
\hline WAIVER & 4 \\
\hline STATUTE & 4 \\
\hline PLEA & 4 \\
\hline INFRINGEMENT & 2 \\
\hline FACTS (OF THE & 2 \\
CASE) & \\
\hline
\end{tabular}

Table 5: General legal terms in ICC

On the other hand, the ICC text is comparatively more formal and ritualistic than the $\mathrm{CMR}$ one as concerns the variety and number of formulae : not only are binomials fairly present -- with examples such as 'null and void', 'fairly and impartially' and 'facts and circumstances' --, but several incorporations from Latin have also been found -mutatis mutandis, prima facie, ex aequo et bono, addendum, inter alia, ipso facto, de jure, de facto, quorum-, as well as two incorporations from French (compositeur and vis-à-vis). There is also a substantial number of words of archaic origin and/or polysyllabic -50 types in all- mainly of Old French ('party', 'claim', 'agreement', 'payment', 'commence/commencement', 'guarantee', 'counsel') and Latin origin ('transmit/transmission', 'terminate/termination', 'evidence', 'condition') but also from Middle French ('court') and Anglo-French ('pleading'). Compositions of adverbials are also more frequent and varied than in the previous subcorpus, with 25 combinations of there+preposition - 'thereto', 'thereof' ', 'thereafter' ', 'thereby', 'therein', 'therewith' and 'thereon' - and here+preposition, such as 'hereinafter' and 'hereby'. Apart from the formulaic use of 'shall' (with 169 occurrences) perceived in the previous subcorpus, the ritualistic hue of the text is also present in such archaic collocations as 'pursuant to', 'insofar as', 'notwithstanding', 'without prejudice to' and 'by virtue of'.

Regarding syntax, the ICC subcorpus contains 233 sentences, with an average of 36.03 words per sentence, a slightly lower figure than the result obtained in the CMR subcorpus. The sentences are not as long as the ones in the CMR corpus, even if there 
are exceptions, like certain clauses that impose a condition with 'if', 'where', 'in the event of', 'once', 'provided', 'by+ -ing and 'unless'). These sentences contain embedding structures similar to those in the CMR:

[If any party against which a claim has been made does not submit an Answer, or raises one or more pleas concerning the existence, validity or scope of the arbitration agreement or concerning whether all of the claims made in the arbitration may be determined together in a single arbitration Qualification 1], the arbitration shall proceed and any question of jurisdiction or of whether the claims may be determined together in that arbitration shall be decided directly by the arbitral tribunal [main (coordinate) sentence], [unless the Secretary General refers the matter to the Court for its decision pursuant to Article 6(4) Qualification 2]. (94 words)

In general, there is a prevalence of subordinate sentences, expressing contrast ("although duly summoned"), cause ("as the Court may decide"), place ("the country where the notification or communication is deemed to have been made"), purpose ("so that the arbitral tribunal may make decisions as to costs"), condition ("provided that they are not contrary to any agreement of the parties") and relative clauses ("the basis upon which the claims are made"). Still, the longer sentences are clearly segmented into paragraphs and divided into subsections of the type (a), (b), (c) separated by a semicolon or a comma, as illustrated by this 194-word extract from Article 4:

The Request shall contain the following information:

a) the name in full, description, address and other contact details of each of the parties;

b) the name in full, address and other contact details of any person(s) representing the claimant in the arbitration;

c) a description of the nature and circumstances of the dispute giving rise to the claims and of the basis upon which the claims are made;

[........]

h) all relevant particulars and any observations or proposals as to the place of the arbitration, the applicable rules of law and the language of the arbitration.

Finally, there are 43 passive constructions which mostly refer to the making of claims (e.g., "irrespective of whether such claims are made under one or more than one arbitration agreement", or "unless any claims are made under Article 7 or 8 in which case Article 36(4) shall apply"), or to the interpretation of the Rules, as in all the cases with "be deemed to be" (e.g., "the notification or communication is deemed to have been made", or as in "The date [...] shall, for all purposes, be deemed to be the date of the commencement of the arbitration").

\subsection{Discursive level}

The discursive elements of professional language are visible at the outset in the supraorganisation or macrostructure which organizes the text into parts and according to 
topic, thus facilitating reader access to global comprehension (Trosborg 1997: 145146). The normative macrostructural rigidity of the texts under scrutiny constitute a predetermined structure that is not susceptible to change, due to the hermeneutical impact that it has on the interpretation of texts that have not been written to be read, but construed and implemented.

The Convention has eight Chapters topically distinguished and preceded by a Preamble, by way of an enacting formula. The Chapters are divided into Articles, some of which are organised in numbered sub-articles. Sometimes these are divided into paragraphs preceded by a letter, especially in the case of Article 6, which articulates the particulars in the consignment note, or Article 17, which enumerates the risks of loss or damage that the carrier is exempt from. Theoretically, organizing the terms of legislation in this way permits users to locate the provisions or details that they need in an unequivocal and easier manner. Such a distribution obeys to a pre-established organization with stereotyped formulae and conventional schemas which are usually present in international instruments at large.

The arrangement of the ICC Rules also shows a visible, coherent organization. There are eight unnumbered sections that categorize the terms and conditions of the different provisions by topic, as in the Convention. Unlike the CMR, however, articles in the ICC text also include explicit headings dealing with each topic and arranging the different categories in a proper sequence. Despite the syntactic density that characterizes the arbitration text, the labelling of its parts makes it easier for the reader to process content, since the numbered or lettered paragraphs correspond to the different parts of a complex sentence. There is a further subdivision into sub-articles (in numbers) and sub-sections (in letters), which also contributes to intratextuality within the text, i.e., the mechanisms of self-reference that integrate its parts, and which make the Rules a united whole.

Additionally, the discursive function is intrinsic to language and exists to construe both propositional and interpersonal aspects into a linear and coherent whole, as Hyland and Tse underline: "With the judicious addition of metadiscourse, a writer is able to not only transform a dry, difficult text into coherent, friendly prose, but also relate it to a given context and convey his or her personality, credibility, audience-sensitivity, and relationship to the message" (2004: 157). As a result, the concept of metadiscourse has been used by researchers to trace patterns of interaction and analyse different aspects of language in use. It has usually and prototypically been linked to areas other than law and its genres, such as, academic writing and press discourse. Nevertheless, SalmiTolonen has recently used the concept of metadiscourse in the area of the law (2014: 63-86) to explain how these mechanisms determine the success of communication between law-makers and law-takers of international instruments. She adapts Hyland's categories to the area of law in an attempt to discern how law-makers make it easier, through use of textual devices, for law-takers to understand a particular text. Though she draws the difference between interactive (purely textual) and interactional (interpersonal) metadiscourse markers, the scope of the present paper bears on the 
former (endophorics, transitions, frames, glosses and evidentials) which are considered as facilitators of discourse construction.

When adapted to the context of the law, endophoric markers can be described as the linguistic elements that refer to the earlier materials in the text, so as to support the argument and help law-takers understand the text better (e.g., 'under', 'in accordance with', 'specified in', etc.). Frame markers, on the other hand, are words or phrases that sequence the text, labelling the text stages (e.g., 'the first', 'the second') or announce a discourse goal, framing it with respect to the rest (e.g., 'for the purposes of', 'where any agreement', 'where the parties have agreed'). Transition markers, on the other hand, express semantic and structural relationships between discourse stretches and help readers interpret pragmatic connections by explicitly signalling express relations (of addition, comparison or consequence) between main clauses (Dafouz, 2008: 97). They are mostly conjunctives and adverbial phrases such as 'in addition', 'but', 'therefore', and 'likewise'. Code glosses are the next category of metadiscourse markers; as Hyland (2005: 52) states, code glosses are "textual devices that supply additional information by rephrasing, explaining or elaborating what has been said, to ensure the reader recovers the writer's intended meaning" (e.g., 'namely', 'in other words', 'such as', or simply punctuating devices such as a colon or parenthesis). And finally, evidentials refer to the sources of information from other legal texts. The utility of evidentials in law is illustrated with connections in the text to other legal sources that may constitute the legal background for the text at hand.

The results obtained at this level (acquired with the aid of MonoConc Pro and by means of manual tagging) are shown in Table 6 , which presents the number and types of discursive markers and their verbalization in the corpus.

\begin{tabular}{|c|c|c|c|}
\hline Category & Function & ICC & CMR \\
\hline $\begin{array}{l}\text { ENDOPHORIC } \\
\text { MARKERS }\end{array}$ & $\begin{array}{l}\text { Reference to } \\
\text { other parts of the } \\
\text { text }\end{array}$ & $\begin{array}{l}\text { in accordance with } \\
\text { the Rules of Arbitration } \\
\text { of the ICC } \\
\text { under the Rules/the } \\
\text { arbitration } \\
\text { agreement/Article } 6 \\
\text { as specified in the } \\
\text { Rules/in Article } 4(3) \\
\text { referred to in article/The } \\
\text { Rules... } \\
\text { pursuant to Article } 33 \\
\text { subject to the } \\
\text { provisions... } \\
\text { Total: } 88\end{array}$ & $\begin{array}{l}\text { As specified in/under article.. } \\
\text { Where the provisions are applicable.. } \\
\text { In accordance with the provisions... } \\
\text { Subject to the provisions... } \\
\text { Under paragraph... } \\
\text { Referred to in article/paragraph... }\end{array}$ \\
\hline $\begin{array}{l}\text { FRAME } \\
\text { MARKERS }\end{array}$ & $\begin{array}{l}\text { Sequencing } \\
\text { devices, } \\
\text { topicalizers }\end{array}$ & $\begin{array}{l}\text { where claims are made } \\
\text { under more than one } \\
\text { arbitration agreement. } \\
\text { Where the parties have } \\
\text { agreed to submit to } \\
\text { arbitration under the } \\
\text { Rules. } \\
\text { Total: } 29\end{array}$ & $\begin{array}{l}\text { For the purposes of this Convention. } \\
\text { The first copy shall be handed to the } \\
\text { sender, the second shall accompany the } \\
\text { goods and the third shall be retained by } \\
\text { the carrier } \\
\text { Where under this article the carrier is } \\
\text { not under any liability } \\
\text { Total: } 28\end{array}$ \\
\hline
\end{tabular}


Opacity in international legal texts: generic trait or symbol of power?

\begin{tabular}{|c|c|c|c|}
\hline Category & Function & $I C C$ & CMR \\
\hline $\begin{array}{l}\text { TRANSITION } \\
\text { MARKERS }\end{array}$ & $\begin{array}{l}\text { Relations of } \\
\text { addition, } \\
\text { comparison or } \\
\text { consequence } \\
\text { between main } \\
\text { clauses }\end{array}$ & $\begin{array}{l}\text { the arbitration shall } \\
\text { proceed and any } \\
\text { question of jurisdiction } \\
\text { (...) may be determined.. } \\
\text { The Court may also } \\
\text { appoint... } \\
\text { Unless otherwise } \\
\text { agreed... } \\
\text { Total : } \mathbf{6 3}\end{array}$ & $\begin{array}{l}\text {, but no further damage shall be } \\
\text { payable... } \\
\text { liability shall also be determined in } \\
\text { accordance with ... } \\
\text { Furthermore, in such a case } \\
\text { In addition, the carriage charges (...) } \\
\text { shall be refunded } \\
\text { Total: } 37\end{array}$ \\
\hline $\begin{array}{l}\text { CODE } \\
\text { GLOSSES }\end{array}$ & $\begin{array}{l}\text { Elaboration of } \\
\text { propositional } \\
\text { meanings }\end{array}$ & $\begin{array}{l}\text { The following provisions } \\
\text { shall apply.... } \\
\text { (The Request for } \\
\text { Joinder) } \\
\text { Colon+enumeration } \\
\text { Total: } 16\end{array}$ & $\begin{array}{l}\text { As follows... } \\
\text { The following } \\
\text { particulars/conditions/circumstances.... } \\
\text { Colon+enumeration } \\
\text { Total:38 }\end{array}$ \\
\hline EVIDENTIALS & $\begin{array}{l}\text { Reference to } \\
\text { other texts }\end{array}$ & $\begin{array}{l}\text { Appendices annexed to } \\
\text { the Rules } \\
\text { Total: } 6\end{array}$ & $\begin{array}{l}\text { The Convention on Road Traffic } \\
\text { Total:1 }\end{array}$ \\
\hline TOTAL & & 202 & 157 \\
\hline
\end{tabular}

Table 6. Discursive markers in our corpus. (Adapted from Salmi-Tolonen, 2014).

Figure 3 presents the overall interactive activity in either text, whereas Figure 4 illustrates more graphically the contents in Table 6 and visually emphasizes our findings regarding textual marker structures and typology in the subcorpora.

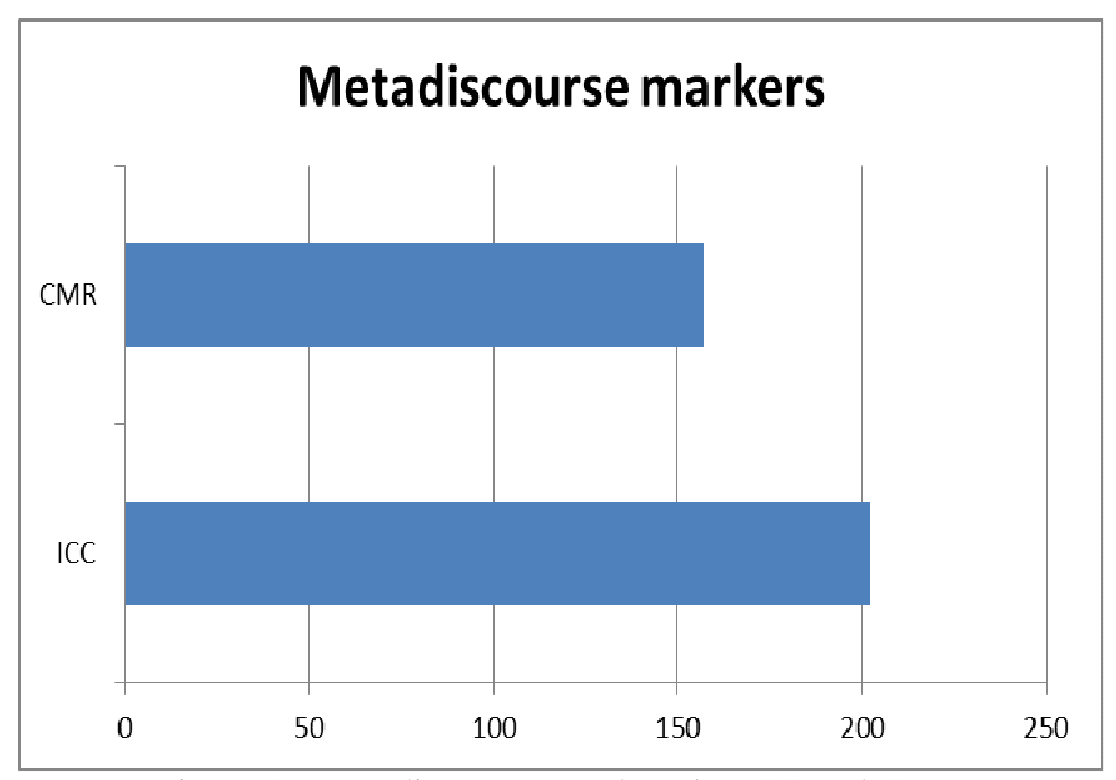

Figure 3: Metadiscourse markers in ICC and CMR 


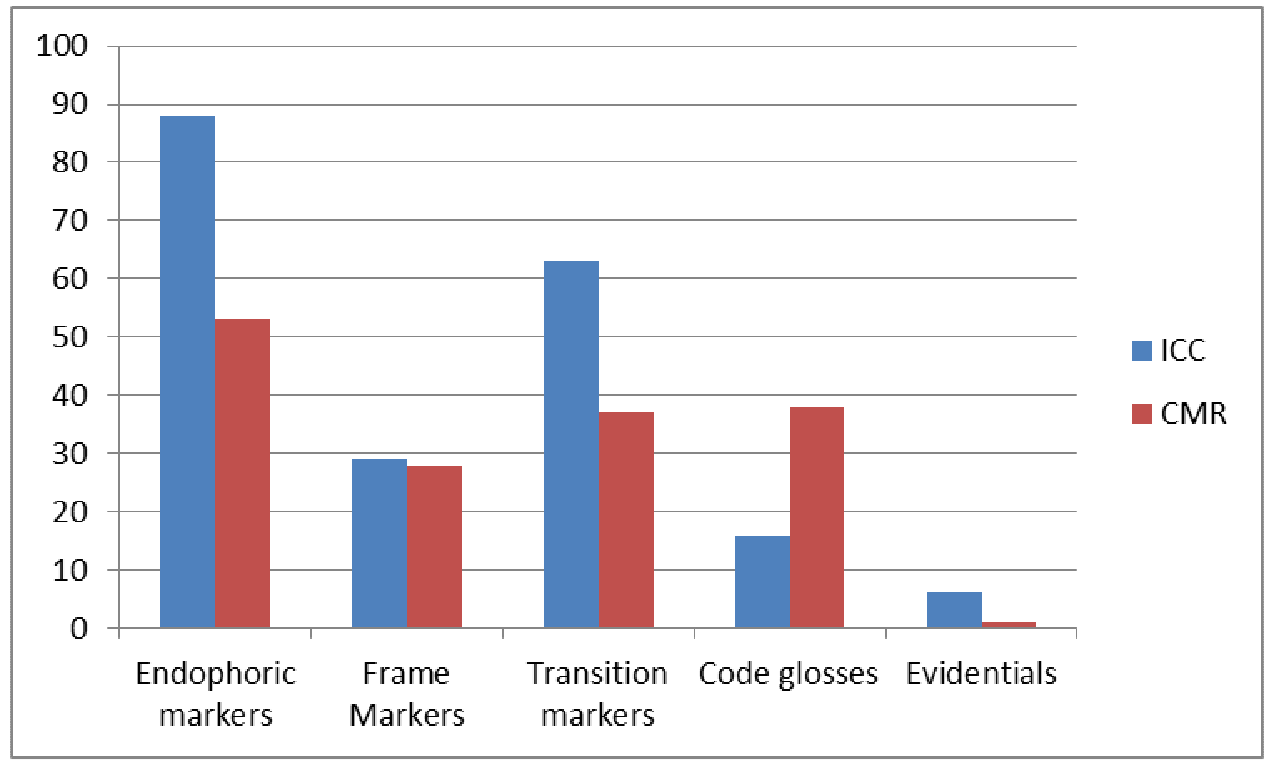

Figure 4: Typology of metadiscourse markers in ICC and CMR

According to Dafouz, readers, in general, prefer to be guided through texts with the aid of metadiscoursive markers (2008: 108), rather than to have to reconstruct and reinterpret the text without any explicit signposting. This is the case of the ICC rules, which show the highest number of interactive markers overall, potentially making it a more 'readable' text for its users. These markers are mainly of the endophoric kind, appearing in the shape of expressions prototypical of legislative texts (such as 'under' or 'in accordance with'). They are aimed at giving consistency and coherence to the discourse, and portraying the substance of the text as a reality, as a 'substantial' normative source. As such, they contribute to the reification of the text itself in the belief that the CMR is an independent, 'living' entity with the power and capacity to issue norms. Reification, according to Lukács (1971), is the fallacy that allows for the conception of abstract entities - such as legal texts- as if they were concrete, real events, or physical entities, thus disengaging the addressers of such texts as the 'intellectual' originators of the ideas behind them. Though endophorics are not all that abundant in the CMR subcorpus, it does nevertheless, present a much more varied array of constructions of this kind, which convey the impression of the Convention as the autonomous and legitimate, sole issuer of duties and prerogatives.

Transition markers are the second type of discourse marker most present in the corpus. These divide and/or connect the texts into logical sequences and are, again, more varied in the CMR but more abundant in the ICC. They also take the archetypical shape that markers do in legal discourse: 'but', for example, appears in the three texts as a connective device, but also indicates exceptions and qualifications to the wording of the stipulations. 'Also' has the contrary effect, expressing additions to those stipulations.

As far as glosses are concerned, these are deployed to reformulate or exemplify textual materials, in our texts mainly through the usage of parentheses and colons 
followed by lists of explanations. The CMR text presents frequent and varied use of glosses, whereas the ICC text shows a lesser presence of explanations and clarifications. This may be due to the clearer macrostructural arrangement of the Convention, which sacrifices glosses and favours graphetic divisions, and because the ICC is a document where the conceptual world depicted is better followed through intratextual references, such as endophorics, or through transitions.

Frame markers are also present in the corpus in such typical expressions of legislative discourse as, 'for the purposes of' or 'where', and constitute indicators of discourse acts within the texts, articulating semantic or structural relations between their different parts. In this sense, they are similar to, or compatible with endophorics, inasmuch as they constitute discoursal mechanisms that materialize meaningfulness of the texts as bodies of norm. As a consequence, and due to the specific character of the text, frame markers are frequent in the solid world of rules that the ICC and the CMR represent.

Finally, evidentials show a modest but clear presence in both texts, as markers of the intertextuality indexes that signify that legal concepts are to be interpreted in the framework of other texts. Using evidentials, as Hyland puts it, is "the perceived credibility that readers grant to writers" (2005: 67), but the scarcity of this device in our corpus is a clear signal of the solidity that law-makers in this case wish to bestow upon their own texts: for the law-makers of the CMR and ICC, the documents in question are intended to stand by themselves as sufficient sources of law for the law-taker.

\subsection{Pragmatic or social level}

As indicated at the beginning of this work, legal genres are textual means through which an authoritative set of institutions that constitute the legal community as a whole regulate social behaviour at large. Power is a significant determinant of strategic choice or lack of choice in genres, and pragmatic choices in institutional discourse are related to the modulation of the degree of imposition and the social distance and relative powers of participants, their reciprocal rights and obligations. There are, thus, natural asymmetries which are not immediately evident in the communicative event that is the issuing of norms by law-makers and their reception by law-takers, as users of the law. This dissymmetry finds its expression in English statutory texts mainly through speech acts which Trosborg divide into regulative acts and constitutive rules, according to their function, i.e., to regulate or convey legal effect, respectively (Trosborg, 1995: 35-37). According to Cao (2007), Evangelisti Allori (2008) and Garzone (2008), these regulatives and constitutive rules of the law are conveyed through modal verbs -mainly the mandatory and constitutive 'shall' and 'shall not', and the facultative 'may'- as "the major grammatical tool" to express the fuzzy area that surrounds power relations in legal documents (Evangelisti Allori, 2008: 80). In the present article we will measure the slippery area that assigns power levels in the normative texts under scrutiny through a taxonomy formulated according to the studies by Trosborg (1995), Cao (2007), 
Garzone (2008) and Evangelisti Allori (2008). Accordingly, modals expressing power and imposition in legal texts have been divided into the following categories:

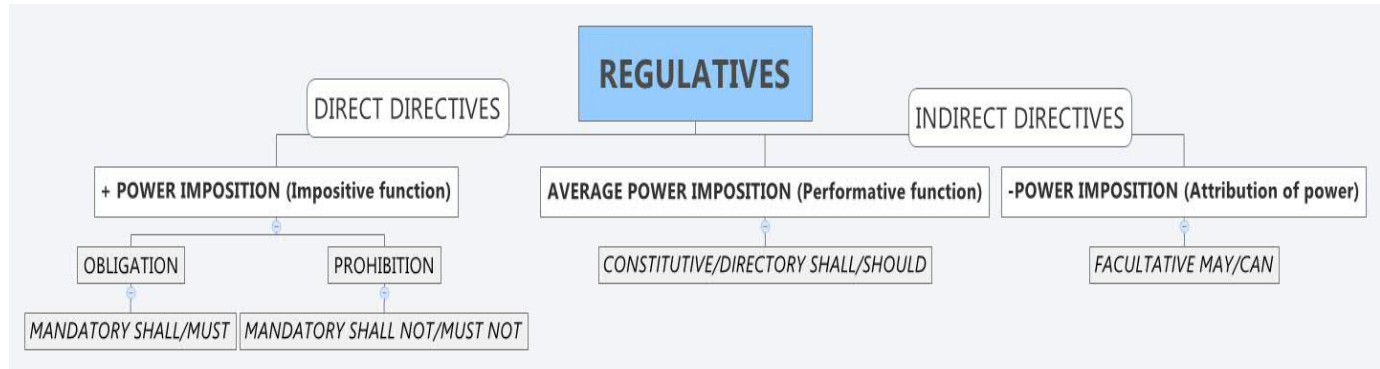

Figure 5. Power imposition and modality in legal discourse

As can be seen in Figure 5, power relations in this paper are represented on a scale from a higher to a lower degree of imposition. Maximum power imposition is stated through direct directives with the utmost impositive force (Trosborg, 1995) and expressed with the mandatory 'shall' and 'must'. In fact, mandatory 'shall/shall not', according to Cao (2007:116) are used to impose duties and prohibit conduct, but in present-day provisions 'must/must not' are increasingly used with the same impositive force to make legislative language more accessible and less ambiguous to the law-taker. On the other hand, 'shall' is used in a directory sense (and not in a regulatory or mandatory sense) when it is aimed at declaring legal effects. It then acquires the performative force of a constitutive rule, aimed at generating a new status quo in the order of things (Evangelisti Allori, 2008: 81). 'Should' is also included in this group, since, according to Trosborg (1995: 43), it rarely has the illocutionary force of a directive, indicating 'weakness' in the expression of obligation. Finally, the lesser degree of power imposition is expressed with 'may' and 'can', which have a facultative function since they either attribute power and confer rights and privileges or grant permission. The results of our analysis are shown in Figure 6 and Table 7:

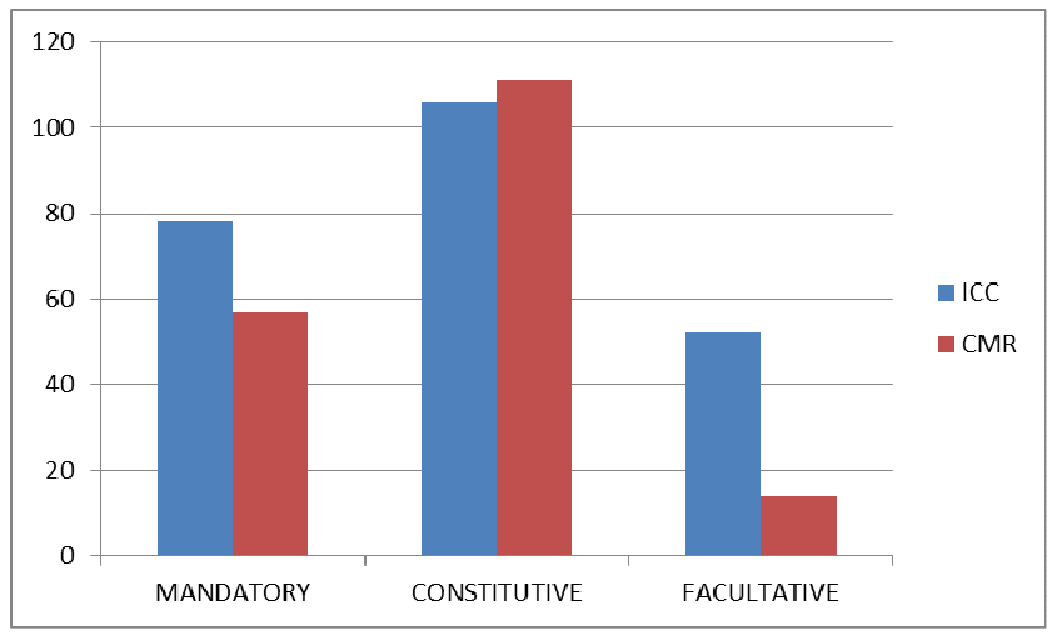

Figure 6: Speech acts in ICC and CMR 


\begin{tabular}{|c|c|c|c|c|}
\hline SUBCORPUS & MANDATORY & CONSTITUTIVE/DIRECTORY & FACULTATIVE & TOTAL \\
\hline ICC & $\begin{array}{l}\text { OBLIGATION: } \\
\text { SHALL: } 68 \\
\text { MUST:9 } \\
\text { PROHIBITION: } \\
\text { SHALL NOT : } 1 \\
\text { MUST NOT:0 }\end{array}$ & $\begin{array}{l}\text { SHALL: } 90 \\
\text { SHALL NOT: } 11 \\
\text { SHOULD:5 }\end{array}$ & $\begin{array}{l}\text { MAY:50 } \\
\text { CAN:2 }\end{array}$ & 236 \\
\hline CMR & $\begin{array}{l}\text { OBLIGATION: } \\
\text { SHALL:47 } \\
\text { MUST:0 } \\
\text { PROHIBITION: } \\
\text { SHALL NOT :10 } \\
\text { MUST NOT:0 }\end{array}$ & $\begin{array}{l}\text { SHALL:94 } \\
\text { SHALL NOT:13 } \\
\text { SHOULD:4 }\end{array}$ & $\begin{array}{l}\text { MAY: } 14 \\
\text { CAN: } 0\end{array}$ & 182 \\
\hline
\end{tabular}

Table 7. Power imposition and modality in ICC and CMR

As we can see above, overall speech act activity is higher in the ICC subcorpus, mainly occurring in both subcorpora by way of constitutive rules. More specifically, the ICC reunites the highest levels of maximum and minimum power imposition, whereas the CMR subcorpus presents the highest number of constitutive rules. Mandatory expressions are substantially more present in both subcorpora than facultative ones, indicating that these texts are much more instruments of power imposition than of right attribution. This would explain the ubiquity of 'shall' in its mandatory, but also constitutive or regulatory modality. As regards 'shall' in constitutive rules, this modal verb is the performative marker which has the illocutionary force of establishing the limits and boundaries of the prescriptions and faculties in the two texts. This is especially true in the CMR, where 'the Convention' contains a substantial number of 'shall' sentences (as in "This Convention shall apply" or "this Convention shall be null and void", among many others). In this way, the regulatory instrument assumes the main role in creating a new state of affairs. The strategy of rendering human something that is not is a clever scheme to conceal the document's lack of balance: the obligations and rights imposed by the text are not always directly assigned to the parties, and it is the instrument itself that takes on a life of its own, distributing obligations and rights and creating boundaries in a more impersonal way. In contrast, in the ICC subcorpus, constitutive rules are mostly expressed through 'shall+passive' constructions, as in "[....] shall be supplied/sent/deemed [....]". Constructions of this type are also present in the CMR, but, as seen at the formal level, they are fewer in number. As remarked elsewhere in this paper, passives are also common devices used to belie the stringency of the law, dissipating the force behind the imposition of obligations and prohibitions on the parties.

If we concentrate upon direct directives of obligation, these, again, are also mostly realized through the use of 'shall', 'must' having a negligible presence in the corpus. In the ICC subcorpus, nevertheless, obligations and prohibitions are equitably distributed among its several participants, namely the 'Parties' as a whole, the Claimant and the Respondent separately, the Tribunal of Arbitrators, the Court and the Secretary General. This is characteristic of a truly ADR process, where all the parties would agree as to its development, and regulations have to be negotiated at some point. It is not so in the 
case of the CMR, where the burden of imposition is sustained mainly by the carrier and, in a much lesser measure, by the sender and the consignee.

Finally, the assignment of rights and granting of privileges is expressed by means of 'may' in both subcorpora, but much more present in the case of the ICC -again with the same even distribution among the several parties involved in the arbitration processand less so in the case of the CMR, where discretionality is more anonymous, taking the shape of 'the Parties' or 'the persons', as in "The parties may enter in the consignment note $[\ldots .$.$] ", or "The person so entitled may [....]".$

\subsection{Discussion of results}

The results at textual level demonstrate that both texts share the defining traits of legal discourse. Lexically, the ICC shows more specificity than the CMR, and more signs of rituality. In line with this argument, it may be worth pointing out that the International Court of Arbitration of the ICC does not itself resolve disputes; it administers the resolution of disputes by arbitral tribunals set up in accordance with its arbitration rules and is the only body authorized to do so; it is also responsible for the scrutiny and approval of arbitral awards. Despite the higher hybridity expected of this type of text and the resulting tendency towards greater lexical and syntactic "plainness", lexical precision may be very necessary in a context where meanings need to be clear and well delimited to be understood by both specialised and lay parties. In contrast, the apparent lexical simplicity of the CMR may be devious: with the exception of terms like 'consignment', 'consignee' (both incorporated into English in the 17th century, with the development of sea cargo) or 'claimant', none of the specialised terms possesses any intrinsic univocity and their presence may, hence, be found in general language too. However, and particularly in the group relating to road transport, the terms have a high specificity of meaning and well defined senses. Definition clauses are normally added in normative texts of this kind to describe who is meant to be 'the carrier', 'the consignee' and 'the sender'. The apparent simplicity of the terms, their recognisability and the fact that they could have an equivocal translation or interpretation for the lay person, make them even more obscure and undistinguishable than conventional, monosemic terms of art. This is also true of the lexis in the ICC, in the sense that only two words such as 'waiver' and 'joinder' can be said to be totally univocal in meaning, the others acquiring their specificity in the light of the inside world that the process of arbitration is meant to regulate. The panorama changes slightly but significantly as regards syntax, and the CMR proves to be the more complex subcorpus, with longer and syntactically involved sentences. Lengthy sentence structures is true of both subcorpora, however, because if the average length of legal sentences is generally estimated at 50 to 80 words per sentence (Gustaffson, 1975; Hiltunen, 1984), several constructions in both of the texts in question exceed this length by far. The same may be said about syntactic complexity, both subcorpora showing qualification insertions and embeddings, mainly of the conditional type. 
At discourse level, however, the way in which length and complexity are administered in the two texts is visibly different, since in the ICC there is a graphetic and topical segmentation of paragraphs, clearly aimed at making the text more comprehensible and easier to process cognitively. This is evident when examining the macrostructural division of either text, with obvious differences in graphetic disposition. If the CMR is intended as a text of reference where data are to be found in an unequivocal manner in Chapters and Articles, this is even more so in the ICC, where Articles are further divided into sections. These, in turn, are sub-segmented and labelled, ostensibly to make the text more user-friendly for its prospective lay users. Additionally, an analysis of the presence of metadiscourse markers in the text confirms that the ICC makes use of greater rhetorical signposting to allow readers to reconstruct and reinterpret the text, mainly in the form of endophorics, but also with abundant transitions. The lexical specificity and the syntactical involvement of this subcorpus are here downtoned by these markers, which organize information in a coherent and convincing way, making it easier for law-takers to follow the text. The accentuated use of these metadiscourse devices and the scarcity of external references to other texts also underline the intratextual rather than intertextual character of both subcorpora. Intratextual reference is a typical phenomenon that distinguishes Common Law texts from Continental ones (Orts, 2015), since the former holds that the text is an autonomous entity to be regarded and interpreted in the light of the text itself. In contrast, the open-textured nature of legal drafting which is prototypical of the Continental tradition requires the text to be supported by the normative framework in which it stands.

Finally, the pragmatic level plainly reveals the authentic nature of the corpus. It shows that, even if there is a sizeable number of mandatory expressions with 'shall' in both texts, constitutive rules are more abundant, especially in the CMR. The ICC is virtually a prescriptive text with more mandatory expressions than the Convention, the permissions, obligations and promises in it contained being divided among the different personalia in the document, i.e., the Parties, the Court and the Tribunal of Arbitrators. It also grants rights and concessions to those same characters, though to a lesser degree. In contrast, with regard to the CMR, it is mainly the living entity of the Convention which imposes 'universal' obligations and penalties (and, in a much lesser measure, prerogatives) to the carrier, the sender and the consignee. Overall, however, 'shall' in its performative function directs, 'objectively' and behind scenes, the way in which the legal process is going to take place in either text. The results match the number of passive constructions present at textual level, and point at the impersonal vocation of legal discourse: a symbol of the impartiality of the law and its institutional weight, performative 'shall', mostly in passive constructions or with inanimate subjects, is significantly present in our corpus as an index of the concealed power imposition in both texts. 


\section{Conclusions}

A study of two different international legal texts -the Geneva Convention on the Contract for the International Carriage of Goods by Road, and the Arbitration Rules of the International Chamber of Commerce-, undertaken with a view to unveiling the nature of their complexity, has rendered satisfactory results. As prototypical examples of the role of English as the medium of global legal discourse, the texts show the traits that distinguish the complex and all-inclusive discourse of Anglo-Saxon Common law at large, at the same time that they present the hybridity that characterizes texts which are born in a context of negotiation between nations. As we underlined above, the 'pure' or 'hybrid' nature of text has an incidence on its relative complexity, since 'pure' international texts are imposed on the community, while meaning in hybrid texts has to be negotiated and are, hence, more clearly understood by the participants. Additionally, both texts show the natural power asymmetries between interactants that take place in institutional discourse, which is essentially normative, since it does not describe but obliges, gives instructions or confers rights (Salmi-Tolonen, 2014: 64). However, the communicative purpose of either genre, which obeys to the ultimate intentions of the communities that issue them, is what configures their discursive and textual organization. Hence, and despite the common features shared by the two texts (since they both have a primarily prescriptive nature, also sharing the higher porosity of hybrid texts), the institutions from which they are originated -the United Nations Commission for Europe (UNECE) that issues the CMR Convention, and the ICC Court of International Arbitration- are not like phenomena, and neither are their purposes. The former is a UN body that promotes pan-European economic integration, and through the CMR it aims at standardizing the norms that govern the carriage of goods by road and the liability of carriers. The latter is the largest and most diverse business organization in the world and its Rules present one of the many ways and means of arbitration, competing with those offered by the rest of the arbitration institutions in the world such as those of the London Court of International Arbitration, or the ones propounded by the American Arbitral Association, for instance. Arbitration being generally a consensual process (i.e., parties are encouraged to agree to settle their differences), and a flexible one -as compared to most court procedures-, the guiding principle of the Rules is to leave the parties to conduct their arbitration as they wish. The Convention, on the other hand, is to be interpreted as a uniform, universal text, applied in the same way by all the courts of the countries that adhere to it. These major differences reflect the radically different communicative purposes of ICC and CMR, the way in which each text has been drafted (their dissimilarities in readability and comprehensibility), and the subtle linguistic and discursive devices through which law-makers seek to control and dominate their audience, the law users. 


\section{Notes}

1. https://www.law.cornell.edu/wex/critical_legal_theory.

2. The signatories of the Convention are Belarus, Belgium, Bosnia-Herzegovina, Bulgaria, Denmark, Estonia, Finland, France, United Kingdom, Greece, Netherlands, Ireland, Italy, Kazakhstan, Croatia, Latvia, Lithuania, Luxembourg, Morocco, Moldova, Norway, Poland, Portugal, Romania, Russia, Switzerland, Slovakia, Slovenia, Spain, Sweden, Tajikistan, Serbia, Czech Republic, Tunisia, Turkmenistan, Turkey, Germany, Hungary, Uzbekistan and Austria.

3. This is the case of the Baltic Exchange's -BIMCO's- Charter Parties and Bills of Lading, or the insurance policies of Lloyd's Institute of Underwriters, which are implicitly 'imposed' on the business world at large, but written solely in the purest of English legalese.

\section{References}

Alcaraz, Enrique and Brian Hughes (2002): Legal Translation Explained. New York: Routledge.

Barnet, Michael and Raymond Duvall (2004): Power in Global Governance. Cambridge: Cambridge University Press.

Breeze, Ruth (2013): Corporate Discourse. London: Bloomsbury.

Breeze, Ruth, Maurizio Gotti and Carmen Sancho-Guinda (eds) (2014): Interpersonality in Legal Genres. Bern: Peter Lang.

Bhatia, Vijay K. (2004): Worlds of Written Discourse. London: Continuum.

Born, Gary (2001): International Commercial Arbitration: International and USA Commentary and Materials. New York: Kluwer Law International.

Bourdieu, Pierre (1991): "On Symbolic Power". In John B. Thompson, ed., Language and Symbolic Power. Pierre Bourdieu. Cambridge: Polity Press, 163-170.

Butt, Peter (2002): "The Assumptions behind Plain Legal Language. At the Heart of Communication". 4th Biennial conference, Toronto, Canada: Plain Language Association InterNational (PLAIN).

Cao, Deborah (2007): Translating Law. Toronto: Multilingual Matters.

Crystal, David (1997): English as a Global Language. Cambridge: Cambridge University Press.

Crystal, David and Derek Davy (1969): Investigating English Style. London: Longman.

Cutler, Claire (2003): Private Power and Global Authority: Transnational Merchant Law in the Global Political Economy. Cambridge: Cambridge University Press.

Dafouz, Emma (2008): "The pragmatic role of textual and interpersonal metadiscourse markers in the construction and attainment of persuasion: A cross-linguistic study of newspaper discourse". Journal of Pragmatics 40: 95-113.

Doyle, Mike (2003): "Discourses of employability and empowerment: Foundation Degrees and 'Third Way' discursive repertoires" [Image]. Retrieved from http://www.leeds.ac.uk/educol/documents/00002421.htm

Evangelisti Allori, Paola (2008): "The Linguistic Formulation of Power: Modality and Power relations in Two Sets of Sports-related Arbitration Rules". In V.K. Bhatia, C. Candlin and P. Evangelisti Allori, eds., Language, Culture and the Law. The Formulation of Legal Concepts Across Languages and Cultures. Linguistic Insights Series, 64. Bern: Peter Lang, 75-97. 
Fairclough, Norman (2014): Language and Power (3rd edition). London: Longman.

Focarelli, Carlo (2012): International Law as Social Construct: The Struggle for Global Justice. Oxford: OUP.

Fowler, Robert, Bob Hodge, Gunther Kress and Tony Trew (1979): Language and Control. London: Routledge.

Fuertes-Olivera, Pedro-A., Marisol Velasco-Sacristán, Ascensión Arribas-Baño, Eva Samaniego-Fernández (2001): "Persuasion and advertising English: metadiscourse in slogans and headlines". Journal of Pragmatics 33: 1291-1307.

Garner, Bryan A. (2001): Legal Writing in Plain English. Chicago: The University of Chicago Press.

Gibbons, John (2004): “Taking legal language seriously”. In Gibbons, John, V. Prakasam, K. V. Tirumalesh and Hemalatha Nagarajan, eds., Language in the Law. New Dehli: Orient Longman, 1-16.

Goodrich, Peter (1987): Legal Discourse: Studies in Linguistics, Rhetoric, and Legal Analysis. New York: St. Martin's Press.

Gotti, Maurizio (2008): "The Formulation of Legal Concepts in Arbitration. Normative Texts in a Multilingual, Multicultural Context". In V.K. Bhatia, C. Candlin and P. Evangelisti Allori, eds., Language, Culture and the Law. The Formulation of Legal Concepts Across Languages and Cultures. Linguistic Insights Series, 64. Bern: Peter Lang, 23-45.

Hammell, Andrew A. (2008): "Legal Translation, the Plain Language Movement, and English as a Lingua Franca", in F. Olsen, A. Lorz and D. Stein eds., Language and Law: Theory and Society, 275-291. Düsseldorf: Düsseldorf University Press. Retrieved from: http://works.bepress.com/andrew_hammel/9

Hermans, Theo (1996): "Norms and the Determination of Translation: A Theoretical Framework". In R. Álvarez and M.-C. Vidal, eds., Translation, Subversion and Power. Clevedon: Multilingual Matters, 25-51.

Hillier, Tim (1998): Sourcebook on Public International Law. London: Routledge.

Hyland, Kenneth (2005): Metadiscourse: Exploring Interaction in Writing. London: Continuum.

Hyland, Kenneth and Polly Tse (2004): "Metadiscourse in academic writing: A reappraisal". Applied Linguistics, 25(2): 156-177.

Kairys, David (ed.) (1990): Introduction to the politics of law: a progressive critique. New York: Basic Books.

Klabbers, Jan and Mortimer Sellers (2008): The internationalization of law and legal education. Dordrecht: Springer Science \& Business Media.

Kress, Gunther and Robert Hodge (1979): Language as Ideology. London: Routledge.

McDowell, Gary (2010): The Language of Law and the Foundations of American Constitutionalism. Cambridge: Cambridge University Press.

Lukács, Georg (1971): History and Class Consciousness. Cambridge, MA: MIT Press.

Mirzaee, Sepideh and Hadi Hamidi (2012): "Critical Discourse Analysis and Fairclough's Model". ELT Voices, 2 (5).

Orts Llopis, María Ángeles (2015) "Legal English and Legal Spanish: The Role of Culture and Knowledge in the Creation and Interpretation of Legal Texts". ESP Today 3(1): 1-134.

Palmirani, Monica, Ugo Pagallo, Pompeu Casanovas and Giovanni Sartor (2011): "Approaches to the Complexity of Legal Systems - Models and Ethical Challenges for Legal Systems, Legal Language and Legal Ontologies, Argumentation and Software Agents". International 
Opacity in international legal texts: generic trait or symbol of power?

Workshop AICOL-III, Held as Part of the 25th IVR Congress, Frankfurt am Main, Germany. Revised Selected Papers.

Salmi-Tolonen, Tarja (2011): "Proactive Law and Alternative Dispute Resolution Mechanisms". In Sorsa, Kaisa, ed., Proactive Management and Proactive Business Law: A Handbook. Course material from Turku University of Applied Sciences 6, Turku.

Salmi-Tolonen, Tarja (2014): "Interpersonality and Fundamental Rights". In R. Breeze, M. Gotti and C. Sancho Guinda, Interpersonality in Legal Genres. Linguistic Insights series, 191. Bern: Peter Lang, 303-328.

Sarangi, Srikant and Stefan Slembrouck (2014): Language, Bureaucracy and Social Control. London: Routledge.

Siegel, Alan and Irene Etzkorn (2013): Simple: Conquering the Crisis of Complexity. London: Hachette UK.

Tiersma, Peter M. (1999): Legal Language. Chicago: The University of Chicago Press.

Trosborg, Anna (1995): "Statutes and Contracts: An Analysis of Legal Speech Acts in the English Language of the Law". Journal of Pragmatics 23: 31-53.

Trosborg, Anna (1997): "Translating Hybrid Political texts". In Trosborg, Anna ed., Text Typology and Translation, 6, 145-345. 